\title{
Catherine MAYEUR-JAOUEN, Histoire d'un pèlerinage légendaire en islam. Le mouled de Tantâ du xiiie siècle à nos jours
}

Paris, Aubier, 2004, 270 p.

\section{Emma Aubin-Boltanski}

\section{(Q) OpenEdition}

\section{Journals}

\section{Édition électronique}

URL : http://journals.openedition.org/assr/2375

DOI : 10.4000/assr.2375

ISSN : $1777-5825$

\section{Éditeur}

Éditions de l'EHESS

Édition imprimée

Date de publication : 1 avril 2005

Pagination : 113-202

ISBN : 2-7132-2044-0

ISSN : 0335-5985

\section{Référence électronique}

Emma Aubin-Boltanski, « Catherine MAYEUR-JAOUEN, Histoire d'un pèlerinage légendaire en islam. Le mouled de Tantâ du xiiie siècle à nos jours ", Archives de sciences sociales des religions [En ligne], 130 | avril - juin 2005, document 130.19, mis en ligne le 01 décembre 2005, consulté le 21 septembre 2020. URL : http://journals.openedition.org/assr/2375; DOI : https://doi.org/10.4000/assr.2375 


\title{
Catherine MAYEUR-JAOUEN, Histoire d'un pèlerinage légendaire en islam. Le mouled de Tantâ du xiiie siècle à nos jours
}

Paris, Aubier, 2004, 270 p.

\author{
Emma Aubin-Boltanski
}

1 Ce livre se propose de faire l'histoire et l'anthropologie de la religion populaire égyptienne à travers un événement religieux majeur, « un merveilleux observatoire des mutations de l'Égypte depuis la période mamelouke » : le pèlerinage (mouled) de Sayyid al-Badawî (m. 1276). La fête se déroule à Tantâ, la quatrième ville d'Égypte, située à michemin entre Le Caire et Alexandrie. Elle est fixée sur le calendrier solaire, en octobre, au moment de la récolte du coton. Alors qu'historiens et anthropologues des années 1970 et 1980 prévoyaient, comme conséquence inéluctable du Réformisme musulman, la disparition progressive des dévotions entourant les saints, Catherine Mayeur-Jaouen démontre, dans cet ouvrage, que le culte des saints constitue toujours aujourd'hui une part importante de la religion ordinaire de la grande majorité des Égyptiens.

2 En six chapitres, l'auteure, historienne et arabisante, dresse le portrait du saint le plus populaire d'Égypte, Sayyid al-Badawî ( $2^{\mathrm{e}}$ chap.), offre une description détaillée de la confrérie que ses disciples fondèrent peu après sa mort ( $3^{\mathrm{e}}$ chap.) et fait l'historique des principales phases de l'évolution du mouled entre le $\mathrm{XIII}^{\mathrm{e}}$ et le $\mathrm{xx}{ }^{\mathrm{e}}$ siècle $\left(4^{\mathrm{e}}, 5^{\mathrm{e}}\right.$ et $6^{\mathrm{e}}$ chap.). Le propos est illustré par des photographies prises lors des mouleds de 1992 et de 2002, ainsi que par des cartes du Delta et de la ville de Tantâ.

3 L'ouvrage commence par un exposé minutieux du mouled de Tantâ en 2002. Par cette description au rythme saccadé et haletant, l'auteure nous fait pénétrer dans le monde tourbillonnant du pèlerinage. Le lecteur suit les pèlerins dans leurs préparatifs et leur installation dans le campement de Sîgar, situé à proximité de Tantâ. La fête débute un vendredi et s'achève le jeudi soir suivant par la "Grande nuit ", une montée en 
intensité progressive rythmée par les dhikrs et les dévotions rendues au saint par une foule immense.

«Un saint ne devient pas saint, il l'est de toute éternité, et toute sa vie n'est qu'un dévoilement progressif de son identité, parfois d'abord cachée », explique C. MayeurJaouen. Qui fut Sayyid al-Badawî ? Comment faire la part entre le personnage mythique façonné au fil des siècles et le Badawî historique ? Comment ce saint, dont la renommée de son vivant ne dépassait pas les frontières de Tantâ, en est-il venu à devenir « un saint musulman archétypal et le saint égyptien par excellence»? C. Mayeur-Jaouen retrace les principaux traits de la vie du saint en s'appuyant sur l'hagiographie foisonnante qui lui fut consacrée. Cette littérature prit toute son ampleur tardivement, entre le $\mathrm{XV}^{\mathrm{e}}$ et le XVII ${ }^{\mathrm{e}}$ siècles, sous la plume de disciples tels que Sha'ranî (m. 1565), 'Abd al-Samad (écrite en 1619) et Halabî (m. 1635). Du personnage historique on sait peu de choses si ce n'est à quelle période il vécut et la date de sa mort. Au regard de l'Histoire, cette figure sainte constitue donc un mystère: elle s'est construite peu à peu, par hagiographies successives modulées en fonction des époques.

Dans les premières hagiographies, qui lui sont consacrées, Badawî est présenté comme un saint échevelé, hirsute, fou, aux jeûnes sévères, aux yeux flamboyants. Il est "l'Homme à la bedaine ", l'homme des excès, tout à la fois capable d'une formidable gloutonnerie et d'une ascèse extraordinaire : il peut jeûner 40 jours et 40 nuits. Son visage est dissimulé par deux voiles, ce qui lui vaut un second surnom : «l'Homme aux deux voiles ». Certains de ses disciples expliquent cet accoutrement peu ordinaire par son origine bédouine que son nom, «Badawî », atteste. Pour d'autres, le saint masquait ainsi son visage irradié par la lumière divine et l'éclat trop aveuglant de son regard capable de foudroyer ses disciples. Il est également "l'Homme de la terrasse», un étrange soufi qui vécut sur un toit de Tantâ. De cette hauteur, il se consacrait à la contemplation du soleil et recevait ses disciples, ainsi que des dévots venus chercher réconfort auprès de lui. La puissance de ce saint exceptionnel est également attestée par son célibat. Ce trait n'est pas, en islam, une condition nécessaire de la sainteté. Dans le cas de Badawî, paradoxalement, il constitue la preuve d'une virilité telle qu'aucun mariage ne peut l'endiguer. Il fait de lui le saint par excellence des filles à marier, des femmes en mal d'enfant ou torturées par les douleurs de l'enfantement.

6 À la fin de la période mamelouke (1450-1500), alors que l'Ahmadiyya, la confrérie fondée par le principal disciple de Badawî, 'Abd al-'Âl (m. 1333), connaît un grand succès, les dévots du saint sont amenés à une relecture et une réécriture de la vie du Maître. Les disciples insistent tout particulièrement sur la généalogie du saint que l'on dit originaire de La Mecque et descendant du Prophète. Ils s'emploient également à souligner sa filiation rifấite en lui attribuant un passage initiatique en Irak. Les hagiographies de cette époque renforcent les liens du Maître avec Ahmad al-Rifầî (m. 1175) et 'Abd al-Qâdir al-Jilânî (m. 1166) les fondateurs des deux grandes confréries, la Rifầiyya et la Qâdiriyya. Le saint hirsute devient alors un pôle puissant et gigantesque.

$7 \mathrm{Au}$ XIX ${ }^{e}$ siècle, orientalistes et archéologues européens se sont également emparés du personnage pour, sous couvert de scientificité, contribuer fortement à l'élaboration d'une nouvelle facette de son mythe. Certains ont fait de lui la trace d'un dieu païen et de son pèlerinage, les restes d'une fête de l'Antiquité. D'autres ont cru découvrir sous les voiles de Badawî un saint chrétien islamisé. Pour étayer ces reconstructions historicistes, aucune preuve ne peut être avancée. À la fin du XIX ${ }^{e}$ siècle, deux thèses adverses apparaissent. Également infondées, elles trouvent leur explication dans le 
contexte de l'occupation britannique (à partir de 1882) et de la présence européenne croissante en Égypte. Toutes deux visent à récupérer le souvenir des croisades du XIII ${ }^{\mathrm{e}}$ siècle et à le cristalliser autour du saint : pour les Européens d'Égypte, Badawî fut l'un des croisés de Saint-Louis, converti à l'islam ; pour les Égyptiens, au contraire, il n'était autre qu'un valeureux soldat menant le jihad contre les croisés. Le Badawî adversaire des croisés, ennemi des chrétiens et des Européens, rencontre une très large adhésion. Son succès est à peine écorné par les virulentes accusations des réformistes musulmans adversaires du culte des saints. Ces derniers propagent une nouvelle théorie au début du $\mathrm{xx}^{\mathrm{e}}$ siècle faisant de Badawî un " espion chi'ite » qui aurait joué un rôle occulte pour le compte des Fatimides ismaéliens. À partir de cette époque, le Maître de Tantâ devient « le saint le plus aimé et le plus honni d'Égypte ».

8 Autour du culte d'Ahmad al-Badawî s'est formée l'une des plus importantes confréries soufies d'Égypte, l'Ahmadiyya. L'une des grandes forces de cet ouvrage est de démontrer que c'est à la fois par le biais de son assise terrienne et grâce à l'appui des puissants que l'Ahmadiyya acquit l'essentiel de sa force. À l'origine, les disciples de Badawî ne forment pas une confrérie organisée, mais un cercle attaché à la figure charismatique de leur Maître. Ils sont communément appelés les «Compagnons de la Terrasse ». Ce n'est qu'après 1450 que le terme Ahmadiyya commence à désigner la confrérie. Au début, cette dernière rassemble surtout des ruraux paillards et illettrés. Les premiers Ahmadî sont volontiers provocants, réputés être des transgresseurs de la loi. Ils font scandale. Ils sont accusés de mœurs suspectes. Les critiques à leur encontre apparaissent dès l'époque mamelouke. À ces accusations la confrérie elle-même répond par des réformes. C'est qu'elle n'est pas uniquement composée de disciples ignorants et frustres. La réalité est bien plus complexe et le temps joue en faveur d'un recrutement de plus en plus diversifié et large. À l'époque ottomane, parmi les Ahmadî notoires, apparaissent en nombre ulémas et écrivains. Des soufis de formation Khalwatî, une confrérie réputée pour son austérité et son orthodoxie, deviennent Ahmadîs. Au XIX siècle, la dévotion pour le Maître de Tantâ est si massive qu'elle unit tous les Égyptiens dans un même flot. À cette époque, Badawî devient le saint national, et l'Ahmadiyya constitue la confrérie égyptienne type. C. Mayeur-Jaouen décrit les rouages de cette organisation, dirigée par un khalifa réputé descendre du principal disciple de Badawî, 'Abd al-'Âl. Elle constitue la confrérie soufie la plus nombreuse d'Égypte par la quantité de branches depuis longtemps indépendantes. Une fédération lâche dont le mouled forme l'épine dorsale.

9 Selon la légende, le mouled de Badawî est né peu après les obsèques du saint mort le jour anniversaire du Prophète Muhammad: le 12 rabît ${ }^{\imath}$. Dans un premier temps, il semble que ce soit avant tout le mawlid al-Nabî (anniversaire de Muhammad) qui ait été célébré auprès de Badawî. Ce qui vaut à ce dernier cet autre surnom: «Porte du Prophète ». Parce qu'elle connaît une immense popularité $a u x^{e}$ siècle, la fête s'autonomise par rapport au mawlid al-Nabî. Elle est alors fixée sur le calendrier solaire. Signe de son succès, la fête locale devient un " petit hajj " pour les dévots qui ne peuvent faire le déplacement à La Mecque. La légende veut que sept mouleds au tombeau de Badawî équivalent au hajj. Le mouled né de la ferveur populaire n'a pris son ampleur que grâce au pouvoir politique. En retraçant l'histoire du pèlerinage, l'auteure met en lumière l'alliance étroite entre pouvoir politique et religion populaire ; entre confrérie et gouverneur, entre cheikhs et émirs. 
$10 \mathrm{Au} \mathrm{xIx}$ siècle, le mouled atteint son apogée comme foire et comme fête. Jamais il n'a déplacé autant de monde, jamais il n'a été aussi indiscuté. Il bénéficie de la pacification du Delta par la mise au pas des Bédouins et des mutations décisives que connaît l'Égypte sous la dynastie des vice-rois et des khédives issus de Méhémet Ali. À cette époque l'extension de la culture du coton permet l'accentuation du rôle commercial de Tantâ et son essor démographique. L'arrivée du chemin de fer en 1854-1856 joue un rôle décisif. La ville de Badawî devient alors une étape importante entre le Caire et Alexandrie. Le mouled est l'occasion d'une grande foire internationale où se côtoient des marchands de toutes nationalités. Tantâ devient florissante et acquiert une grande notoriété. C'est à cette époque que l'hagiographie transforme Badawî en héros guerrier vainqueur des croisés et que, pour les Européens, Tantâ gagne une solide réputation de fanatisme.

$11 \mathrm{Au} \mathrm{xx}^{\mathrm{e}}$ siècle, le mouled connaît une métamorphose radicale: sécularisation, désenchantement $\mathrm{du}$ monde, politisation de l'islam, rejet du culte des saints, accélération des rythmes agraires, exode rural vont contribuer à mettre fin à son immense éclat: aujourd'hui il "n'est plus que l'ombre de son prodigieux passé ». Badawî lui-même est comme ébranlé : « il n'est plus le géant intangible à l'intercession eschatologique duquel tous ajoutaient foi ». Le héros, vainqueur des croisés, est affaibli par le succès insolent des Européens. Il devient la cible privilégiée des adversaires du culte des saints. Le saint perd de sa plasticité et de son infinie capacité à incarner de multiples islams : islam des pauvres, des riches, des ignorants, des Ulemas... Au xx $\mathrm{x}^{\mathrm{e}}$ siècle, ses nombreuses facettes deviennent «contradictions» et s'excluent l'une l'autre: "soufis réformés des villes, paysans sans instruction, islamistes de combat, bourgeois sécularisés, jeunesse sans avenir, c'est à chacun son Badawî ». Ce phénomène est, entre autres, le résultat de l'immense diffusion qu'a connu son hagiographie au XIX siècle grâce au développement de l'imprimerie. La tradition écrite prend le pas sur la tradition orale et tend à figer le personnage dans un rôle et une posture définitive.

Depuis les années 1950, les pèlerins du mouled sont moins nombreux. Les causes de ce déclin sont multiples et de différentes natures, politique, religieuse et économique. Au moment de la création des États nations, le tracé des frontières constitue une entrave au déplacement des dévots. La foire internationale disparaît pour être remplacée par le petit commerce local. Elle devient un marché régional dont l'importance, à l'échelle même du Delta, diminue. La crise économique, que connait l'Égypte depuis les années 1980, n'a fait qu'accentuer ce phénomène de repli. De plus, le Réformisme musulman a eu un impact non négligeable sur la fête. On assiste à une désaffection progressive d'une grande partie des villageois du Delta pour des rites perçus comme inutiles et contraignants. De leur côté, les citadins affichent de plus en plus ouvertement leur mépris pour des coutumes associées aux ruraux.

13 Cependant l'affection que l'on voue au saint de Tantâ en Égypte n'a pas disparu. Le pèlerinage n'engage plus l'ensemble de la communauté mais devient une affaire personnelle. Signe de ce glissement du collectif vers l'individuel, le déclin du mouled n'implique en rien celui des visites pieuses individuelles (ziyâra) qui peuvent se faire à tout moment de l'année. De plus, le mouled fait aujourd'hui partie intégrante du " patrimoine » national. Il symbolise l'attachement des Égyptiens à leurs saints et aux descendants du prophète. À ce titre il reste un événement important pour l'Égypte. Une nouvelle sorte de pèlerins est apparue: pendant le mouled, des urbains désorientés 
viennent chercher à Tantâ des racines culturelles et religieuses dont ils pressentent qu'elles sont celles de l'Égypte même. 